\title{
Pengaruh CAR, ROA, FDR, dan BOPO terhadap Non-Performing Financing pada Bank Muamalat Indonesia
}

\author{
The influence of $C A R, R O A, F D R$, and $B O P O$ on non-performing financing at \\ Muamalat Indonesia Bank
}

\author{
Dea Apriyani \\ Program Studi D4 Keuangan Syariah, Politeknik Negeri Bandung \\ E-mail: deaapriyani98@gmail.com
}

\section{Ine Mayasari}

Jurusan Akuntansi, Politeknik Negeri Bandung

E-mail: ine.mayasari@polban.ac.id

\section{Mochamad Edman Syarief}

Jurusan Akuntansi, Politeknik Negeri Bandung

E-mail: edman.syarief@polban.ac.id

\begin{abstract}
Muamalat Bank have decline in financial performance. Muamalat Bank lacks capital because it provides too much corporate financing which has an impact on increasing non-performing financing. Besides that, the net profit of Muamalat Bank in 2019 decreasec significantly, namely by 92\% and its operating costs rached Rp490 billion. This research was conducted to know the effect of the variable Capital Adequacy Ratio (CAR), Retum On Assets (ROA), Financing to Deposit Ratio (FDR), and Operating Expenses per Operating Income (BOPO) on Non-Performing Financing (NPF) at Bank. Muamalat. Indonesia. The sample used is the quarterly reportpublished on the official website of Bank. Muamalat. The research method used is quantitative research with multiple linear regression analysis and is supported by the Eviews software version 10 as a data processing application. The results of this study indicate that $C A R$ and $\mathrm{RO} A$ bave a negative and significant effect on the NPF of Bank Muamalat. Meanwhile, FDR and BOPO have a positive and significant effect on $N P F$.
\end{abstract}

Keywords: NPF, CAR, ROA, FDR, BOPO

\section{Pendahuluan}

Menurut hasil penelitian yang dilakukan oleh (Kholis, 2017), Perkembangan keuangan Islam didunia mendapat banyak perhatian di berbagai benua dan wilayah. Perbankan Syariah menjadi salah satu sistem dalam perekonomian Islam yang paling populer di dunia, asset bank Islam mencapai US $\$ 882$ billion (setara dengan 11.466 trilyun)". Kendati dengan demikian, bank syariah tidak lepas dari permasalahan (Setiawan, 2018). Salah satu yang menjadi permasalahan pada bank syariah yaitu pembiayaan bermasalah atau Non Performing Financing. Menurut (Mufidah, 2016), Non Performing Financing (NPF) merupakan rasio perbandingan antara jumlah pembiayaan yang dinilai bermasalah dengan jumlah pembiayaan yang telah disalurkan bank syariah. Semakin tinggi NPF, maka semakin tidak sehat bank tersebut (Nurazlina \& Mauluddi, 2020).

Pada saat ini Bank Muamalat sedang mengalami penurunan kinerja keungan, hal ini disebabkan karena Bank Muamalat terlalu banyak memberikan pembiayaan untuk korporasi 
misalnya untuk sektor pertambangan sehingga menyebabkan naiknya tingkat NPF. Seperti yang dijelaskan oleh (Purnomo, 2019), bahwa laba bersih Bank Muamalat per Oktober 2019 mengalami penurunan hingga $92 \%$ data tersebut diperoleh dari laporan bulanan yang diterbitkan perseroan, laba bersih Bank Muamalat tercatat Rp 8,14 miliar, atau turun $92 \%$ dari periode yang sama tahun 2018 lalu yang masih mencapai Rp 111,9 miliar. Dan dikutip dari laporan bulanan yang di upload di situs resmi Bank Muamalat bahwa total aset Muamalat per Oktober 2019 tercatat Rp 52,95 triliun yang juga mengalami penurunan dari Oktober 2018 yang mencapai $\mathrm{Rp} \mathrm{54,82} \mathrm{triliun.}$ Pendapatan dari penyaluran dana perseroan di Oktober 2019 mencapai Rp 2,38 triliun dibandingkan pada Oktober 2018, tercatat mengalami penurunan. Pada Oktober 2018 pendapatan dari penyaluran dana mencapai Rp 2,77 triliun. Beban operasional Bank Muamalat pada Oktober 2019 tercatat Rp 499,27 miliar. Sementara laba komprehensif tahun berjalan pada Oktober 2019 mencapai Rp 21,32 miliar. Pada Oktober 2018 lalu, laba komprehensif tahun berjalan perseroan masih mencapai $\mathrm{Rp} 111,90$ miliar.

Untuk melihat perubahan rasio keuangan Bank Muamalat Dibawah ini disajikan tabel yang memperlihatkan perubahan nilai NPF Bank Muamalat.

Tabel. 1 Perubahan tingkat NPF, CAR, ROA, FDR, dan BOPO pada tahun 2018-2019

\begin{tabular}{|l|r|r|r|r|r|r|r|r|}
\hline Rasio & TW I '18 & TW II '18 & TW III '18 & TW IV '18 & TW I '19 & TW II '19 & TW III '19 \\
\hline NPF (\%) & 4.76 & 1.65 & 2.98 & 4.43 & 4.43 & 5.41 & 5.64 \\
\hline CAR (\%) & 10.16 & 15.92 & 12.12 & 13.62 & 12.58 & 12.01 & 12.42 \\
\hline ROA (\%) & 0.15 & 0.49 & 0.35 & 0.11 & 0.02 & 0.02 & 0.02 \\
\hline FDR (\%) & 88.41 & 84.37 & 79.03 & 84.41 & 71.17 & 68.05 & 68.51 \\
\hline BOPO (\%) & 98.03 & 92.78 & 94.34 & 97.68 & 99.13 & 99.04 & 98.83 \\
\hline
\end{tabular}

Sumber: Laporan Triwulan Bank Muamalat, https://www.Bankmuamalat.co.id/ (diolah)

Berdasarkan data diatas rasio-rasio keuangan selalu mengalami perubahan dan terdapat penyimpangan dengan teori yang menyatakan Berdasarkan data diatas rasio-rasio keuangan selalu mengalami perubahan dan terdapat penyimpangan dengan teori yang menyatakan hubungan antara ROA, FDR, CAR, dan BOPO dengan NPF. CAR dan ROA cenderung mengalami penurunan dari tahun ke tahun, apalagi pada tahun 2019 rasio ROA turun mencapai $0,02 \%$. Sedangkan rasio FDR dan BOPO cenderung meningkat, hal ini berarti pembiayaan dan disalurkan terlalu banyak dan kurang memperhatikan prinsip kehati-hatian. Biaya operasional yang dikeluarkannya pun lebih besar dari pendapatan, sehingga bank kurang efisien dan berdampak pada meningkatnya pembiayaan bermasalah.

\section{Kajian Pustaka}

\subsection{Pengertian NPF, CAR, ROA, FDR, dan BOPO}

\section{Non-Performing Financing}

Dalam buku yang ditulis oleh (Muhamad, 2005), Non Performing Financing adalah rasio antara pembiayaan yang bermasalah dengan total pembiayaan yang disalurkan oleh Bank syariah. Berdasarkan kriteria yang sudah ditetapkan oleh Bank Indonesia kategori yang termasuk dalam NPF adalah pembiayaan kurang lancar, diragukan, dan macet (Muhamad, 2005).

$\mathrm{NPF}=($ Pembiayaan Bermasalah $) /($ Total Pembiayaan Yang Disalurkan $) \times 100 \%$

\section{Capital Adquacy Ratio}

Bank Indonesia menetapkan modal CAR yaitu kewajiban modal minimum yang harus selalu dipertahankan oleh setiap Bank sebagai suatu proporsi tertentu dari total Aktiva Tertimbang Menurut Resiko (ATMR) (Muhamad, 2005). Rasio CAR dapat dihitung dengan rumus sebagai 
berikut:

\section{Return On Assets}

Munawir (2002) mengatakan "ROA merupakan perbandingan antara laba sebelum bunga dan pajak dengan total aktiva yang dimiliki perusahaan. Semakin besar ROA suatu perbankan, semakin besar pula tingkat keuntungan yang dicapai Bank tersebut dan semakin baik pula posisi suatu Bank dari segi penggunaan asset". ROA merupakan rasio profitabilitas yang mengukur kemampuan bank dalam menghasilkan laba dari penggunaan seluruh sumber daya atau aset yang dimilikinya. ROA dirumuskan sebagai berikut:

ROA $=($ Laba Sebelum Pajak $) /($ Total Aset $) \times 100 \%$

\section{Financing to Deposite Ratio}

Menurut Muhamad (2005), rasio yang membandingkan antara pembiayaan yang disalurkan dengan dana pihak ketiga dinamakan rasio FDR. Bank dapat dikatakan berhasil dalam menjalankan fungsi intermediasinya apabila rasio FDR bank tersebut besar. FDR merupakan rasio yang digunakan untuk mengukur seberapa besar bank mampu memberikan pembiayaan yang dihimpun dari dana pihak ketiga kepada nasabah pembiayaan (Rohmatunnisa \& Pratiwi, 2020). Rasio FDR tidak boleh terlalu tinggi ataupun terlalu rendah. Hal ini dikarenakan apabila rasio FDR rendah, maka bank tidak mampu menjalankan fungsi intermediasinya secara maksimal. Dan apabila rasio FDR terlalu tinggi hal itu berarti pembiayaan yang disalurkan dari dana pihak ketiga terlalu banyak, dengan melonjaknya pembiayaan maka akan meningkatkan risiko pembiayaan bermasalah (Nugraha \& Arshad, 2020). FDR dapat dirumuskan sebagai berikut :

FDR $=($ Pembiayaan Yang Diberikan $) /($ Dana Pihak Ketiga $) \times 100 \%$

\section{Beban Operasional per Pendapatan Operasional}

Dendawijaya (2009) menjelaskan bahwa, rasio yang digunakan untuk mengetahui tingkat kemampuan menajemen mengontrol biaya operasionalnya disebut rasio BOPO atau rasio efisiensi. Setiap peningkatan biaya operasional akan berakibat pada berkurangnya laba sebelum pajak dan akhirnya akan menurunkan laba atau profitabilitas (ROA) Bank yang bersangkutan (Dendawijaya, 2009). Semakin rendah tingkat rasio BOPO berarti semakin baik kinerja manajemen bank, karena lebih efisien dalam menggunakan sumber daya yang ada di perusahaan (Setyowati, 2019). Berdasarkan Surat Edaran Bank Indonesia No.9/24/DPbS tanggal 30 Oktober 2007, kriteria penilaian tingkat BOPO pada Bank Syariah adalah sebagai berikut:

Tabel. 2 Kriteria Penilaian BOPO

\begin{tabular}{lll}
\hline Peringkat & Besaran Nilai BOPO & Keterangan \\
\hline 1 & BOPO $\leq 83 \%$ & Sangat Baik \\
2 & $83 \%<$ BOPO $\leq 85 \%$ & Baik \\
3 & $85 \%<$ BOPO $\leq 87 \%$ & Cukup Baik \\
4 & $87 \%<$ BOPO $\leq 89 \%$ & Kurang Baik \\
5 & BOPO $>89 \%$ & Tidak Baik \\
\hline
\end{tabular}

Sumber: SE BI No.9/24/DPbS Tahun 2007

Persamaan BOPO ditulis sebagai berikut:

$\mathrm{BOPO}=($ Biaya Operasional $) /($ Penndapatan Operasional $) \times 100 \%$.

\section{Metode Penelitian}

Jenis penelitian ini merupakan penlitian kuantitatif. Metode yang digunakan adalah analisis regresi data time series. Analisis tersebut digunakan untuk mengukur pengaruh variabel CAR, ROA, FDR, dan BOPO terhadap variabel Non Performing Financing. Penelitian ini menggunakan 
pendekatan Ordinary Least Square dan diestimasikan menggunakan metode LS-Least Square (NLS and ARMI) (Ghozali \& Ratmono, 2013). Data sekunder dalam penelitian ini adalah laporan rasio keuangan yang bersumber dari situs resmi Bank Muamalat Indonesia, berupa laporan rasio keuangan dari triwulan 12010 sampai triwulan 3 2019. Dari metode yang sudah disebutkan diatas, maka persamaan regresinya dapat dituliskan sebagai berikut:

$\mathrm{Y}=\alpha+\mathrm{b} 1 \mathrm{X} 1+\mathrm{b} 2 \mathrm{X} 2+\mathrm{b} 3 \mathrm{X} 3+\mathrm{b} 4 \mathrm{X} 4+\mathrm{e}$

Keterangan:

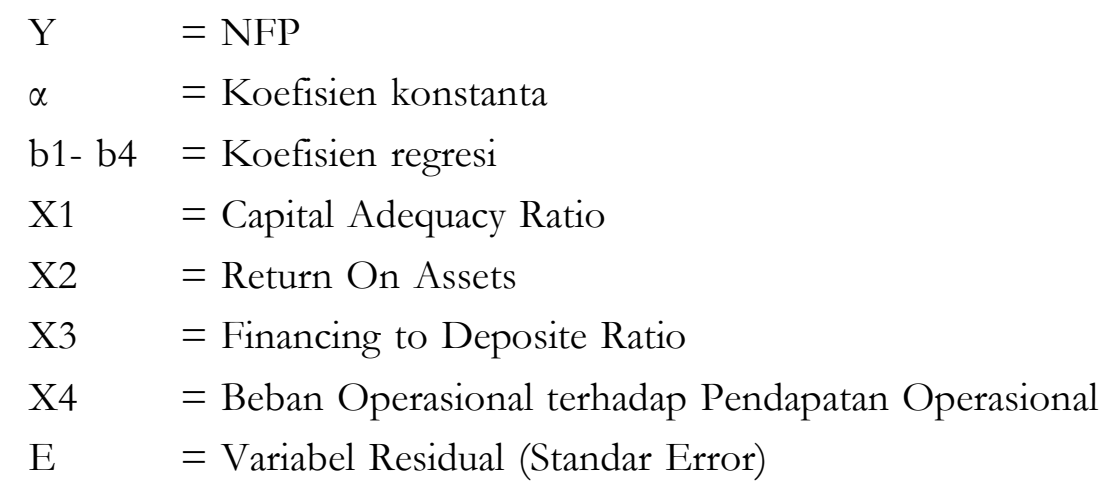

\section{Hasil dan Pembahasan}

\subsection{Hasil Penelitian}

\section{Analisis Regresi Data Time Series}

Analisis Regresi data time series dalam penelitian ini bertujuan untuk mengetahui pengaruh variabel CAR, ROA, FDR, dan BOPO terhadap Non Performong Financing pada Bank Muamalat Indonesia. Pendekatan pada penelitian ini menggunakan Ordinary Least Square. Estimasi pendekatan pada penelitian ini menggunakan metode LS-Least Square (NLS and ARMI). Selain dari itu, model ini sudah terbukti lolos uji asumsi klasik sehingga hasil konsisten dan tidak bias. Dibawah ini disajikan estimasi regresi data time series dengan menggunakan pendekatan Ordinary Least Square:

Tabel. 3 Hasil regresi data time series

Dari hasil olah data diatas diadapatkan hasil regresi dengan persamaan:

\begin{tabular}{lllll}
\hline \hline Variable & Coefficient & Std. Error & t-Statistic & Prob. \\
\hline \hline C & 0.093659 & 0.015699 & 5.965884 & 0.0000 \\
CAR & -0.331098 & 0.122564 & -2.701433 & 0.0107 \\
ROA & -1.386600 & 0.289751 & -4.785492 & 0.0000 \\
FDR & 0.000259 & 0.000125 & 2.067882 & 0.0463 \\
BOPO & 0.862958 & 0.260683 & 3.310371 & 0.0027 \\
\hline \hline & & & & 0.041415 \\
R-squared & 0.525178 & Mean dependent var & 0.015824 \\
Adjusted R-squared & 0.469317 & S.D. dependent var & -5.969000 \\
S.E. of regression & 0.011527 & Akaike info criterion & -5.755723 \\
Sum squared resid & 0.004518 & Schwarz criterion & -5.892478 \\
Log likelihood & 121.3955 & Hannan-Quinn criter. & &
\end{tabular}




$\begin{array}{llll}\text { F-statistic } & 9.401455 & \text { Durbin-Watson stat } & 1.197466 \\ \text { Prob(F-statistic) } & 0.000031 & & \end{array}$

Sumber: Hasil Output Eviews 10

Dari hasil olah data diatas diadapatkan hasil regresi dengan persamaan:

$$
\begin{aligned}
& \mathrm{Y}=\alpha+\beta 1 \mathrm{X} 1+\beta 2 \mathrm{X} 2+\beta 3 \mathrm{X} 3+\beta 4 \mathrm{X} 4+\mathrm{e} \\
& \mathrm{NPF}=0,093659-0.331098(\mathrm{CAR})-1,386600(\mathrm{ROA})+0,000259(\mathrm{FDR})+0,862958
\end{aligned}
$$
$(\mathrm{BOPO})+\mathrm{e}$

Berdasarkan persamaan regresi diatas, maka didapat hasil berikut yang dimana konstansa persamaan regresi yaitu sebesar 0,093659, artinya apabila CAR, ROA, FDR, dan BOPO sebesar 0, maka NPF sebesar 0,093659 dan signifikan pada alpha sebesar 5\% karena probabilitasnya 0,0000 $<$ dari 0,05 .

Koefisien regresi variabel CAR yaitu sebesar -0.331098 , artinya dengan asumsi ROA, FDR, dan BOPO tetap, maka setiap peningkatan CAR sebesar 1\% akan menurunkan NPF sebesar 0,331098 atau $0,33 \%$ dan signifikan pada alpha sebesar 5\% karena probabilitas 0,0107<0,05. Koefisien regresi bernilai negatif menggambarkan bahwa ada hubungan yang negatif antara variabel CAR dengan NPF. Hal ini sejalan dengan pendapat yang beredar bahwa, bank yang mempunyai nilai kecukupan modal yang besar maka bank tersebut akan mampu menutupi kerugian-kerugian operasional bank salah satunya yaitu kerugian yang disebabkan oleh pembiayaan bermasalah.

Koefisien regresi variabel ROA adalah sebesar -1,386600, artinya dengan asumsi CAR, FDR, dan BOPO tetap, maka setiap peningkatan ROA sebesar 1\% akan menurunkan NPF sebesar 1,386600 atau $1,38 \%$ dan signifikan pada alpha $5 \%$ karena probabilitas $0,0000<0,05$. Koefisien nya bernilai negatif sehingga memberi gambaran bahwa ada hubungan negatif antara ROA dengan NPF. Hasil penelitian ini selaras dengan teori yang beredar bahwa, Semakin tinggi ROA maka NPF akan semakin rendah, hal ini karena Bank menekan profitabilitasnya dengan menyalurkan pembiayaan untuk menghasilkan pendapatan.

Koefisien regresi variabel FDR sebesar 0,000259, artinya dengan asumsi CAR, ROA, dan BOPO tetap, maka setiap peningkatan FDR sebesar 1\% akan meningkatkan NPF sebesar 0,000259 atau $0,0002 \%$ dan signifikan pada alpha $5 \%$ karena probabilitas $0,0437<0,05$. Koefisien bernilai positif sehingga menggambarkan hubungan positif antara variabel FDR dengan NPF. Seperti yang dijelaskan oleh (Haifa \& Wibowo, 2015) bahwa, "Pembiayaan yang tinggi lambat laun dapat menurunkan kualitas dari pembiayaan tersebut. Dari segi kuantitas semakin banyak pembiayaan yang dikeluarkan maka, risiko pembiayaan bermasalah/NPF menjadi lebih besar. Jadi semakin tinggi FDR semakin tinggi NPF, demikian sebaliknya".

Koefisien regresi variabel BOPO yaitu sebesar 8.970000, artinya dengan asumsi CAR, ROA, dan FDR tetap, maka setiap peningkatan BOPO sebesar 1\% akan meningkatkan NPF sebesar 0,862958 atau $0,8 \%$ dan signifikan pada alpha $5 \%$ karena probabilitas $0,0027<0,05$. Nilai koefisiennya yaitu positif menggambarkan hubungan positif antara BOPO dengan NPF. Hal ini selaras dengan teori yang beredar bahwa rasio BOPO menggambarkan tingkat efisiensi bank dalam mengontrol biaya operasionalnya. Apabila bank kurang efisien dalam pegontrolan biaya operasional maka bank akan rentan terhadap pembiayaan bermasalah. 


\section{Uji signifikanasi Parsial (Uji Statistik t)}

Hasil uji signifikasi parsial dapat dilihat pada tabel sebagai berikut:

Tabel. 4 Hasil Uji Signifikasi Parsial

\begin{tabular}{|c|c|c|c|c|}
\hline Variable & t-tabel & t-Statistic & Prob. & Kesimpulan \\
\hline CAR & 1.68488 & -2.701433 & 0.0107 & Signifikan pada $\alpha=5 \%$ \\
\hline ROA & 1.68488 & -4.785492 & 0.0000 & Signifikan pada $\alpha=5 \%$ \\
\hline FDR & 1.68488 & 2.067882 & 0.0463 & Signifikan pada $\alpha=5 \%$ \\
\hline BOPO & 1.68488 & 3.310371 & 0.0027 & Signifikan pada $\alpha=5 \%$ \\
\hline
\end{tabular}

Dilihat dari tabel diatas, bahwa nilai t-Statistic CAR adalah sebesar -2,701433 lebih besar dari t-Tabel yaitu sebesar 1,68488 (-2,701433>1,68488) dengan tingkat signifikan 0,0107<0,05. Sementara itu, variabel ROA mendapat nilai t-Statistik sebesar -4785492 lebih besar dari t-Tabel yaitu sebesar 1,68488, dengan tingkat signifkan $0,000<0,05$. Kemudian, variabel FDR mempunyai nilai t-Statistik sebesar 2,067882 lebih besar dari nilai t-Tabel yaitu sebesar 1,68488, dengan tingkat signifikan $0,0463<0,05$. Dan yang terakhir variabel BOPO mempunyai nilai tStatistic sebesar 3,310371 lebih besar dari nilai t-Tabel yaitu sebesar 1,68488, dengan tingkat signifikan 0,0027<0,05. Dari hasil tersebut dapat disimpulkan bahwa variabel CAR dan ROA bepengaruh negatif dan signifikan terhadap NPF. Sedangkan variabel FDR dan BOPO berpengaruh positif dan signifikan terhadap NPF Bank Muamalat Indonesia.

\section{Uji signifikanasi Simultan (Uji Statistik F)}

Tabel. 5 Hasil uji signifikasi simultan

\begin{tabular}{llll}
\hline \hline R-squared & 0.525178 & Mean dependent var & 0.041415 \\
Adjusted R-squared & 0.469317 & S.D. dependent var & 0.015824 \\
S.E. of regression & 0.011527 & Akaike info criterion & -5.969000 \\
Sum squared resid & 0.004518 & Schwarz criterion & -5.755723 \\
Log likelihood & 121.3955 & Hannan-Quinn criter. & -5.892478 \\
F-statistic & 9.401455 & Durbin-Watson stat & 1.197466 \\
Prob(F-statistic) & 0.000031 & & \\
\hline \hline
\end{tabular}

Sumber: Hasil Output Eviews 10

Nilai $\mathrm{F}$ tabel pada $\alpha=5 \%$ dengan numerator $(\mathrm{k}-1)=4$, dan df denominator $(\mathrm{n}-\mathrm{k})=34$, maka diperoleh nilai $F$ tabel sebesar 2,65 untuk nilai $F$ hitung diperoleh 9,401455. Dapat disimpulkan bahwa nilai $\mathrm{F}$ hitung $>\mathrm{F}$ tabel sehingga menolak $\mathrm{H} 0$ dan menerima Ha. Sedangkan dilihat nilai probabilltas hasil regresi diperoleh probabilitas $F$ adalah $0,000031<\alpha=5 \%$ maka menolak H0 dan menerima Ha artinya secara bersama-sama variabel CAR, ROA, FDR, dan BOPO berpengaruh secara signifikan terhadap variabel NPF.

\section{Uji Koefisien Determinasi (R2)}

Tabel. 6 Hasil uji koefisien determinasi

R-squared

0.525178

Adjusted R-squared

0.469317

Sumber: Hasil Output Eviews 10

Dari hasil regresi diperoleh data koefisien determinasi (R2) sebesar 0,525178 yang berarti bahwa 52,51\% variabel terkait dalam penelitian ini yaitu CAR, ROA, FDR, dan BOPO mampu menjelaskan atau berpengaruh terhadap NPF sedangkan sisanya 47,49\% dipengaruhi oleh 
variabel lain diluar penelitian.

\section{Uji Asumsi Klasik}

Uji asumsi klasik pada penelitian ini terdiri dari uji normalitas, uji autokorelasi, uji multikolinearitas, dan uji heterokedastisitas.

\section{Uji Normalitas}

Hasil uji normalitas pada penelitian ini dapat dilihat pada gambar sebagai berikut:

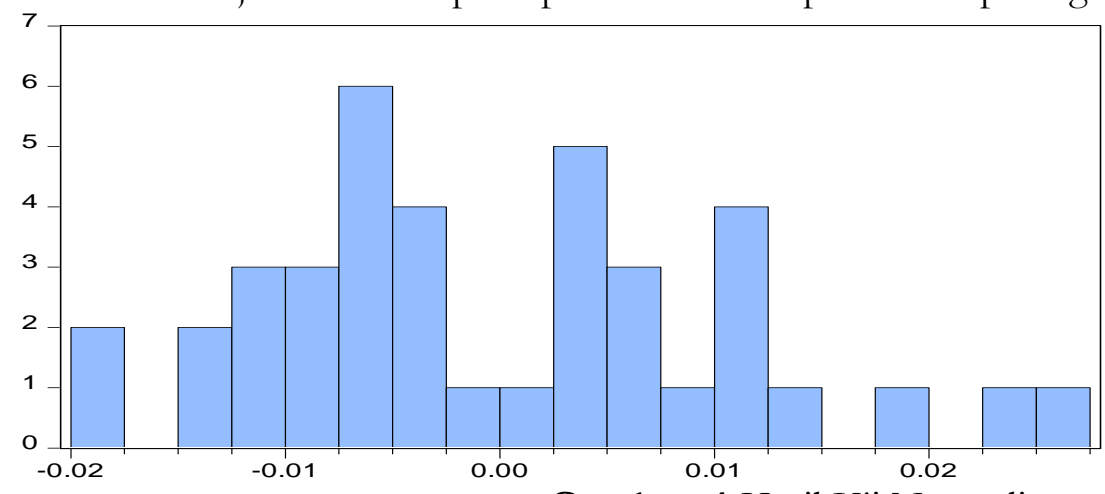

\begin{tabular}{|c|c|}
\hline \multicolumn{2}{|c|}{$\begin{array}{l}\text { Series: Residuals } \\
\text { Sample 2010Q1 2019Q3 } \\
\text { Observations } 39\end{array}$} \\
\hline Mean & $-2.70 e-17$ \\
\hline Median & -0.003045 \\
\hline Maximum & 0.027257 \\
\hline Minimum & -0.019167 \\
\hline Std. Dev. & 0.010904 \\
\hline Skewness & 0.497610 \\
\hline Kurtosis & 2.755056 \\
\hline Jarque-Bera & 1.706995 \\
\hline Probability & 0.425923 \\
\hline
\end{tabular}

Gambar. 1 Hasil Uji Normalitas

Sumber: Hasil Output Eviews 10

Berdasarkan Histogram diatas, dapat dilihat bahwa nilai Probability pada Uji normalitas memperlihatkan 0,425923 yang nilainya $>0,05$. Sehingga dapat disimpulkan bahwa data dalam penelitian ini termasuk data terdistribusi normal karena probability pada uji normalitas memperlihatkan nilai probabilitas signifikansinya lebih besar dari alpha 0,05 (Ghozali \& Ratmono, 2013).

\section{Uji Autokorelasi}

Hasil uji autokorelasi dalam penelitian ini dapat dilihat sebagai berikut:

Tabel. 7 Hasil Uji Autokorelasi

Breusch-Godfrey Serial Correlation LM Test:

\begin{tabular}{llll}
\hline \hline F-statistic & 0.731288 & Prob. F(2,31) & 0.4894 \\
Obs*R-squared & 1.712060 & Prob. Chi-Square(2) & 0.4248 \\
\hline
\end{tabular}

Sumber: Hasil Output Eviews 10

Dari hasil uji autokorelasi diatas, bahwa nilai probabilitas Chi-Square adalah 0,4248 lebih besar dari 0,05 sehingga dapat disimpulkan bahwa data dari penelitian ini bebas dari masalah autokorelasi atau data terdistribusi normal.

\section{Uji Multikolinearitas}

Hasil dari uji multikolinearitas pada penelitian ini dapat dilihat pada tabel sebagai berikut:

Tabel. 8 Hasil Uji Multkolinearitas

\begin{tabular}{lllll}
\hline & CAR & ROA & FDR & BOPO \\
\hline \hline X1 & 1 & 0.1069 & 0.0811 & 0.3788 \\
X2 & 0.1069 & 1 & -0.0293 & -0.0034 \\
X3 & 0.0811 & -0.0293 & 1 & -0.0376 \\
X4 & 0.3788 & -0.0034 & -0.0376 & 1 \\
\hline \hline
\end{tabular}

Sumber: Hasil Output Eviews 10 
Dari hasil uji multikolinearitas diatas dapat dilihat bahwa nilai korelasinya adalah sebesar $0.3788<0,7$ sehingga dapat disimpulkan bahwa variabel independen tidak terjadi maslah multikolinearitas.

\section{Uji Heterokedastisitas}

Dari tabel di bawah ini dapat dilihat hasil uji heterokedastisitas sebagai berikut:

Tabel. 9 Hasil Uji Heterokedastisitas

Heteroskedasticity Test: Glejser

\begin{tabular}{llll}
\hline \hline F-statistic & 0.897316 & Prob. F(4,34) & 0.4763 \\
Obs*R-squared & 3.723969 & Prob. Chi-Square(4) & 0.4446 \\
Scaled explained SS & 2.740797 & Prob. Chi-Square(4) & 0.6021 \\
\hline
\end{tabular}

Sumber: Hasil Output Eviews 10

Dari hasil uji heterokedastisitas dengan menggunakan metode Glejser, nilai probabilitasnya 0,4446 $>0,05$ sehingga dapat disimpulkan bahwa data penelitian ini tidak terjadi gejala heterokedastisitas atau data termasuk data normal.

\subsection{Pembahasan}

\section{Pengaruh CAR terhadap Non-Performing Financing}

Berdasarkan hasil regresi dan uji-t maka dapat disimpulkan bahwa CAR berpengaruh negatif dan signifikan terhadap NPF Bank Muamalat Indonesia. Hasil penelitian ini sesuai dengan penelitian yang dilakukan oleh (Lee dkk., 2019), yang menyatakan bahwa rasio CAR berpengaruh negatif dan signifikan terhadap NPF. Salah satu hal penting dalam rangka pengembangan bisnis dan menampung risiko adalah modal, rasio CAR digunakan untuk mengukur kemampuan bank dalam menanggung risiko dari setiap aktiva produktif yang berisiko (Sa'idah \& Mauluddi, 2018). Rasio CAR yang berpengaruh negatif ini menggambarkan bahwa apabila bank mampu menjaga kecukupan modalnya maka bank akan mampu menanggung kerugian-kerugian yang diakibatkan oleh kegiatan operasional yang berisiko, terutama pembiayaan.

Pengaruh CAR yang negatif terhadap NPF Bank Muamalat juga dapat dilihat secara langsung pada besarnya nilai NPF. Rasio NPF pada tahun 2019 terus meningkat bahkan diatas angka 5\% sedangkan nilai CAR sebesar $12 \%$, walaupun rasio CAR masih di batas aman, akan tetapi bank harus meningkatkan kembali rasio CAR, karena modal yang dimiliki bank saat ini tidak mampu menutupi kerugian yang diakibatkan oleh aktiva yang berisiko. Dengan demikian, pada akhirnya nilai NPF menjadi tinggi.

\section{Pengaruh ROA terhadap Non-Performing Financing}

Berdasarkan hasil regresi dan hasil uji-t dapat disimpulkan bahwa ROA berpengaruh negatif dan signifikan terhadap NPF. Hasil penelitian yang sama ditemukan pada penelitian yang dilakukan oleh (Effendi dkk., 2017), yang menyatakan bahwa rasio ROA berpengaruh negatif dan signifikan terhadap NPF. Hal ini menggambarkan bahwa apabila pembiayaan yang diberikan oleh bank tidak mampu dilunasi oleh nasabah maka hal tersebut akan menjadi risiko pembiayaan yang diterima oleh bank. Sedangkan margin dari pembiayaan merupakan pendapatan utama bank, apabila pendapatan utamanya menurun maka hal tersebut akan menyebabkan tingkat pembiayaan bermasalah meningkat yang pada akhirnya akan meningkatkan nilai NPF

Pengaruh negatif ROA terhadap NPF Bank Muamalat saat ini dapat dilihat secara langsung pada laporan keuangannya. Laba bersih Bank Muamalat turun sangat signifikan dari periode 
sebelumnya yang mencapai $92 \%$, sehingga nilai ROA nya pun menjadi kecil yaitu sebesar $0,02 \%$. Hal itu tentu menjadi ancaman bagi Bank Muamalat karena dengan penurunan ROA menyebabkan naiknya nilai NPF hingga mencapai 5,64\%. Dengan demikian dapat dikatakan bahwa profitabilitas Bank Muamalat sangat rendah, sehingga berakibat pada kenaikan nilai NPF.

\section{Pengaruh FDR terhadap Non-Performing Financing}

Berdasarkan hasil regresi dan hasil uji-t dapat disimpulkan bahwa ROA berpengaruh negatif dan signifikan terhadap NPF. Hasil penelitian yang sama ditemukan pada penelitian yang dilakukan oleh (Effendi dkk., 2017), yang menyatakan bahwa rasio ROA berpengaruh negatif dan signifikan terhadap NPF. Hal ini menggambarkan bahwa apabila pembiayaan yang diberikan oleh bank tidak mampu dilunasi oleh nasabah maka hal tersebut akan menjadi risiko pembiayaan yang diterima oleh bank. Sedangkan margin dari pembiayaan merupakan pendapatan utama bank, apabila pendapatan utamanya menurun maka hal tersebut akan menyebabkan tingkat pembiayaan bermasalah meningkat yang pada akhirnya akan meningkatkan nilai NPF (Hijriyani \& Setiawan, 2017)

Hal ini terbukti pada laporan keuangannya, bahwa Bank Muamalat terlalu banya memberikan pembiayaan misalnya pada sektor pertambangan, sehingga hal tersebut menyebabkan nilai NPF terus meningkat bahkan pada triwulan II tahun 2016 nilai NPF melonjak tinggi hingga 7,23, kenaikan NPF tersebut tentu dipacu pula oleh meningkatnya nilai FDR yang mencapai 99,11\%. Dengan demikian, Bank Muamalat kurang memperhatikan prinsip kehatia-hatian, sehingga pembiayaan yang disalurkan menyebabkan tingginya nilai NPF.

\section{Penutup}

Berdasarkan hasil dari olah data dan juga pengujian hipotesis maka dapat disimpulkan bahwa secara parsial variabel CAR berpengaruh positif dan signifikan terhadap NPF. Hal ini dikarenakan rasio kecukupan modal yang dimiliki oleh Bank Muamalat masih rendah, sehingga bank tidak mampu menutupi kerugian yang diakibatkan oleh pembiayaan bermasalah. Variabel ROA berpengaruh positif dan signifikan terhadap NPF, hal tersebut terjadi karena profitabilitas Bank Muamalat yang rendah dikarenakan ketidakmampuan nasabah untuk membayar angsuran peembiayaan sehingga margin yang didapat menjadi berkurang dan tingkat pembiayaan bermasalah menjadi naik. Kemudian variabel FDR berpengaruh positif dan signifikan terhadap NPF, hal ini disebabkan karena bank terlalu banyak memberikan pembiayaan tanpa memperhatikan prisip kehati-hatian sehingga menyebabkan pembiayaan bermasalah menjadi naik. Dan yang terakhir variabel BOPO berpengaruh positif dan signifikan terhadap NPF, hal tersebut disebabkan oleh ketidakmampuan bank dalam mengontrol biaya operasional, terutama untuk pembiayaan sehingga menyebabkan nilai NPF menjadi tinggi.

Dari pembahasan dan kesimpulan yang didapat, maka ada beberapa saran yang mungkin akan bermanfaat bagi Bank Muamalat diantaranya: 1) Bank Muamalat perlu meningkatkan labanya agar rasio ROA bisa meningkat dengan cara, meningkatkan margin dan tentunya yang masih diterima oleh pasar atau mengurangi biaya. Bank Muamalat dapat meningkatkan penjualan produkproduknya dengan profit margin yang tinggi, atau bank dapat meningkatkan frekuensi penjualan atau meningkatkan perputaran persediaan. Penjualan produk-produk dengan margin tinggi dapat dilakukan kepada nasabah-nasabah loyal. Dengan demikian, Bank Muamalat bisa meningkatkan pendapatan dan tentunya nilai ROA akan naik, pada akhirnya dapat menurunkan tingkat pembiayaan bermasalah atau NPF; 2) Bank Muamalat harus menurunkan tingkat BOPO hal ini bisa dilakukan dengan cara menekan biaya-biaya operasional seperti penggunaan barang cetakan, kertas, tinta. Selain itu Bank harus menekan kembali biaya operasional Sumber Daya Manusia (SDM) serta fokus pada jaringan teknologi informasi yang ada. Dengan efisiensi tersebut dan dibarengi peningkatan income maka rasio BOPO diharapkan akan turun; 3) Hal yang dapat 
dilakukan untuk meningkatkan rasio CAR yaitu bank harus menambah modal dengan cara menjaga kepercayaan para investor agar mereka tetap memberikan modal tambahan untuk bank. Dengan modal tambahan tersebut maka bank akan mempunyai kecukupan modal yang tinggi; 4) Bank Muamalat harus menjaga prinsip kehati-hatian dalam menyalurkan pembiayaan dengan cara melakukan analisa yang mendalam terhadap calon nasabah yaitu dengan unsur 5C (Character, Capacity, Capital, Collateral, dan Condition), agar rasio FDR bisa terkontrol.

Selain itu saran bagi penulis selanjutnya diharapkan dapat menambah variabel penelitian dan menambah metode penelitian selain dari metode yang sudah digunakan. Untuk variabel yang ditambahkan bisa menggunakan variabel pertumbuhan ekonomi, inflasi dan kurs rupiah. hal ini dikarenakan keadaan ekonomi Indonesia saat ini sedang mengalami penurunan akibat pandemic sehingga penelitian lanjtuan mengenai variabel yang mempengaruhi NPF dengan menggunakan variabel yang lebih banyak, diaharapkan dapat memberikan hasil yang lebih maksimal dan saran yang lebih baik lagi untuk Bank Muamalat

\section{Daftar Pustaka}

Dendawijaya, L. (2009). Manajemen Perbankan. Ghalia Indonesia.

Effendi, J., Thiarany, U., \& Nursyamsiah, T. (2017). Factors Influencing Non-Performing Financing (NPF) at Sharia Banking. Walisongo: Jurnal Penelitian Sosial Keagamaan. https://doi.org/10.21580/ws.25.1.1540

Ghozali, I., \& Ratmono, D. (2013). Analisis Multivariat dan EkonometrikaTeori, Konsep, dan Aplikasi dengan Eviews 8. Dalam Universitas Diponegoro.

Haifa, \& Wibowo, D. (2015). Pengaruh Faktor Internal Bank dan Makro Ekonomi Terhadap Non Performing Financing Perbankan Syariah di Indonesia Periode 2010:01 - 2014:04. Jurnal Nisbah, 1 no. 2, 1-14.

Hijriyani, N. Z., \& Setiawan. (2017). Analisis Profitabilitas Perbankan Syariah di Indonesia Sebagai Dampak dari Efisiensi Operasional. Jurnal Kajian Akuntansi, Vol.1, 194-209.

Kholis, N. (2017). Potret Perkembangan Dan Praktik Keuangan Islam Di Dunia. Millab: Jurnal Studi Agama, Universitas Indonesia. https:// doi.org/10.20885/millah.vol17.iss1.art1

Lee, Y. Y., Dato Haji Yahya, M. H., Habibullah, M. S., \& Mohd Ashhari, Z. (2019). Nonperforming loans in European Union: Country governance dimensions. Journal of Financial Economic Policy. https://doi.org/10.1108/JFEP-01-2019-0027

Mufidah, I. A. (2016). Pengaruh Pembiayaan Sektor Ekonomi Primer, Sektor Ekonomi Sekunder, dan Sektor Ekonomi Tersier Terhadap Non Performing Financing (NPF) Pada Perbankan Syariah di Indonesia2010-2015 (Maret). Jurnal Ekonomi Syariab Teori dan Terapan, 3, 402417.

Muhamad. (2005). Managemen Bank Syariah. UPP AMP YKPN.

Munawir, S. (2002). Analisis Informasi Kenangan. Liberty Yogya.

Nugraha, H., \& Arshad, D. (2020). Analisis Faktor-Faktor yang Mempengaruhi FDR Bank Umum Syariah (Studi Kasus PT Bank Muamalat Indonesia Tbk). Journal of Applied Islamic Economics and Finance, 1(1), 37-53.

Nurazlina, L., \& Mauluddi, H. A. (2020). Dampak Faktor Eksternal dan Faktor Internal terhadap Perkembangan Bank Umum Syariah di Indonesia. Journal of Applied Islamic Economics and Finance, 1(1), 97-108.

Purnomo, H. (2019). No Title. cnbcindonesia. www.cnbcindonesia.com/syariah/

Rohmatunnisa, H., \& Pratiwi, L. N. (2020). Pengaruh NPF, FDR, CAR dan Inflasi terhadap 
Penyaluran Pembiayaan Modal Kerja pada BPRS di Indonesia. Journal of Applied Islamic Economics and Finance, 1(1), 137-151.

Sa'idah, S. H., \& Mauluddi, H. A. (2018). Bank Muamalat Indonesia Profitablity Analysis: Study of the Effects of Capital, Asset Quality, Earnings and Liquidity. Jurnal Ekonomi dan Bisnis Terapan, Volume 14, 69-81.

Setiawan, S. (2018). Determinan Penentu Pertumbuhan Dana Pihak Ketiga Perbankan Syariah di Indonesia. Jurnal Maps (Manajemen Perbankan Syariah), 1(2), 1-9.

Setyowati, D. H. (2019). Pengaruh Efisiensi Operasional Terhadap Return On Assets pada Bank Umum Syariah di Indonesia. Jurnal Masharif al-Syariah: Jurnal Ekonomi dan Perbankan Syariah, Volume 4, 39-53. 